\title{
Client, caregiver, and provider perspectives of safety in palliative home care: a mixed method design
}

Ariella Lang ${ }^{1 *}$, Lynn Toon ${ }^{1}$, S Robin Cohen ${ }^{2}$, Kelli Stajduhar ${ }^{3}$, Melissa Griffin ${ }^{4}$, Andrea R Fleiszer ${ }^{5}$, Tony Easty ${ }^{4}$ and Allison Williams ${ }^{6}$

\begin{abstract}
Background: Palliative care clients with complex needs are increasingly choosing to remain at home for their care. Home represents familiarity, presence of supportive family and friends, potential for normalcy and, a safe haven. The palliative care literature although robust is hardly ever linked with safety and home care. Patient safety has been focused predominantly on institutions without a corresponding level of research or safety initiatives in the home care sector. Although a growing body of research has begun to highlight the complexity and multidimensionality of home care safety there is a dearth of understanding of safety issues from the perspectives of clients, caregivers, and paid providers who are responsible for managing and coordinating palliative home care. The aim of this study was to describe the experiences, challenges, and insights regarding safety for adults receiving and providing palliative home care services.
\end{abstract}

Methods: Mixed method design was used to capture the multiple meanings and influences on the broadened conceptualization of home care safety including emotional, social, and functional safety. There were three types of participants in this multi-site study namely palliative home care clients, caregivers, and paid providers. Individual interviews ( $n=33$ ) were conducted in the client's home followed by a photo "walkabout" to describe their daily experiences and routines. Focus groups, three with experienced professionals $(n=25)$ and two with home support workers $(n=11)$ were also conducted.

Results: This study supports the broadened conceptualization of home care safety namely that: the safety of the client and caregiver are inextricably linked; the home is an unregulated and uncontrolled site for providing palliative home care in contrast to hospitals or other institutional settings; and clients and caregivers have the autonomy to live and take risks in their own home.

Conclusion: To ensure quality in palliative home care and to mitigate safety risks the client and caregiver(s) should be considered as the unit of care; caregivers need to be better prepared and trained to manage the complexity of issues; and regular assessments are imperative to monitor and detect changes in the unit of care and their changing needs while respecting their autonomy to make less than safe choices.

Keywords: Palliative home care, Caregiver, Home care, Home care safety, Patient safety, Interpretive description, Mixed methods, Human factors

\footnotetext{
* Correspondence: ariella.lang@sympatico.ca

${ }^{1}$ Victorian Order of Nurses (VON) Canada, 2315 St. Laurent Blvd, Suite 100,

Ottawa, ON K1G 4J8, Canada

Full list of author information is available at the end of the article
}

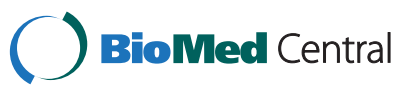

(c) 2015 Lang et al. This is an Open Access article distributed under the terms of the Creative Commons Attribution License (http://creativecommons.org/licenses/by/4.0), which permits unrestricted use, distribution, and reproduction in any medium, provided the original work is properly credited. The Creative Commons Public Domain Dedication waiver (http:// creativecommons.org/publicdomain/zero/1.0/) applies to the data made available in this article, unless otherwise stated. 


\section{Background}

Palliative care clients with complex needs are increasingly choosing to remain at home for their care $[1,2]$. Home represents familiarity, presence of supportive family and friends, potential for normalcy and, a safe haven [3-5]. Home care includes a wide range of services to individuals who need medical or nursing treatments such as wound care and medication management. It also includes assistance with activities of daily living like bathing, dressing, and eating, and/or help with instrumental activities like housework and meal preparation [6].

As is the case throughout Canada, most countries focus on patient safety in the institutionalized care sector. There has not been a corresponding level of research or patient safety initiatives in the home care sector [7]. Moreover, although the literature on palliative care is quite robust, it is hardly ever linked with safety and home care. In 2006, following the first U.S. National Summit on Medical Errors and Patient Safety, the Research Quality Interagency Coordination Task Force produced the first document to link safety and palliative home care [8]. Extending knowledge about safety in palliative home care is important because clients ${ }^{\mathrm{a}}$ receiving end-of-life care, as well as their family and caregivers $^{\mathrm{a}}$, are particularly vulnerable to medical errors and safety lapses for a number of reasons. Palliative clients have increased exposure to medications, treatments and the healthcare system; these clients have more serious effects from errors because they have less reserve with which to overcome the effects and lastly; their disease may have caused cognitive impairments. Palliative clients are often exposed to pervasive patterns of care that run counter to well-substantiated, evidence-based practices including insufficient or inappropriate treatment of pain, depression, dyspnea, and other symptoms that are common with this population, in this context [8]. Family and other caregivers that provide the majority of the care at home are often elderly and contending with their own health problems [6,9]. Caregivers often experience sleep deprivation because they provide around-the-clock care such as administering and managing medications, moving the client, managing medical equipment, and providing intimate personal care such as bathing, toileting, and skin care [10]. This is in stark contrast to how clients are cared for in institutions where there are two or three shifts of paid professionals prepared to provide this kind of care.

Caregivers are often ill-prepared and overwhelmed by the many demands they face, placing them at risk for injury and other negative consequences such as adverse physical, psychological, social, and financial challenges $[11,12]$. Coordinated care, optimal medication regimens, advanced care planning, and bereavement care can all make substantial differences in comfort, rate of exacerbations, and even lifespan [13]. Yet, palliative care clients and their family/caregiver(s) often face a piecemeal array of uncoordinated care elements, making the receipt and provision of home care challenging and fraught with risks [14]. Providing palliative care in the home requires that home be recognized as "a distinct place of care" [15] and not just an extension of an institution. Moreover, the care and safety of palliative clients at home cannot be attended to without including the family and caregiver(s) in the equation [7,16-21].

In Canada, the Victorian Order of Nurses (VON Canada), a national not-for-profit charitable home and community care organization, recognized the gap in knowledge around safety in home care and in collaboration with the Canadian Patient Safety Institute launched several initiatives to begin filling the evidence gap around home care safety. The first initiative was a national roundtable with researchers as well as decision- and policymakers during which consensus was reached around the following: 1) home care safety presents unique challenges requiring a fundamental rethink of the underlying assumptions and guiding frameworks used to examine patient safety in institutional settings [7,22]; 2) the need to "broaden the conceptualization of patient safety" to one that "expands the definition of home care safety beyond the physical safety to include emotional, social, and functional safety (Table 1); and 3) that safety for the client is inextricably linked to the safety of family members, caregivers and providers ${ }^{\mathrm{a}}$ [7]. They recommended that the safety implications for home care be addressed in relation to: service provision for vulnerable clients (e.g. elderly, chronically, and/or terminally ill); ethical considerations for the myriad of daily decisions in home care and the critical role of clients, family, and caregivers as integral members of the healthcare delivery team; and human factors principles for technology within the home care environment [7,21].

Although a growing body of research [7,9,19-21,23-27] has begun to highlight the complexity and multidimensionality of home care safety there is a dearth of understanding of safety issues from the perspectives of clients and caregivers themselves, as well as from the providers who are responsible for managing and coordinating palliative care at home. As such, the research question guiding this study was: What are the experiences, challenges, and insights of adult clients, their unpaid family/caregivers, and their paid providers, regarding safety in palliative home care?

\section{Methods}

Interpretive description methodology [28], which acknowledges the constructed and contextual nature of the health-illness experience, was used to design this study. This grounded approach to articulating patterns 
Table 1 Dimensions of home care safety risks [7]

\begin{tabular}{|c|c|}
\hline & Dimensions of home care safety risks \\
\hline Physical & $\begin{array}{l}\text { Encompasses the physical environment including technology (i.e., oxygen tanks, dialysis, IV's etc.), supplies (i.e. medications, stoma } \\
\text { maintenance, solutions etc.) the diversity of people involved to manage and administer, and relationships with/between them. }\end{array}$ \\
\hline Emotional & $\begin{array}{l}\text { Refers to the psychological impact of receiving and providing care at home. It is often distressing or anxiety-provoking for clients } \\
\text { and caregivers to cope with a myriad of issues (i.e. managing medications, changes in client health status, treatments, and technology). } \\
\text { Fatigue, exhaustion, depression are prevalent and can have tremendous impact on everyone involved. }\end{array}$ \\
\hline Social & $\begin{array}{l}\text { Addresses the idea of where the client lives in the community, who lives with the client, who visits the home, and the nature of } \\
\text { the client's social support network. Potential for decrease in social interactions, loneliness, and isolation from friends and family. } \\
\text { Potential for various forms of abuse is an important consideration for those providing and receiving home care. }\end{array}$ \\
\hline Functional & $\begin{array}{l}\text { Encompasses how health conditions or provisions of care affect activities of daily living, employment, leisure activities. } \\
\text { Potential for diminished capacity to function in your home and community doing what you would normally be able } \\
\text { to or want to do (i.e., shopping, banking, gardening, working etc.) }\end{array}$ \\
\hline
\end{tabular}

and themes emerging in relation to various clinical phenomena, was used to capture the multiple meanings and influences on the social, emotional, functional, and physical safety that play out within the palliative home care experience. This non-categorical qualitative research methodology was useful in contributing to our understanding of how people experience health and illness and focused on what healthcare providers can do to make a difference [28].

The broadened conceptualization of safety in home care that includes physical, emotional, social, and functional safety $[7,21]$ was the framework used to guide this study. Socio-ecological perspectives [29-31] provided an analytic lens to help us understand the increasing complexity and interrelatedness of the concepts of safety, palliative home care, and clinical practice, with the diverse personal and environmental factors and the interrelationships among these factors that influence a given health situation. Aligned with these perspectives is the contribution of human factors principles which considers "human capabilities and limitations in the context of interactive systems of people, tools, technology, and work environments to ensure their safety, effectiveness, and ease of use" [32]. In the case of home care, human factors engineers understand the need to examine the complex issues at play and the potential threats to quality and safety through an analysis of the sensory, physical, and cognitive abilities of providers/ caregivers/clients, required care processes and tools, medical devices and other equipment, and the physical environment in which care takes place. Instead of requiring people to change their behaviour to interact with complex systems, human factors focuses on changing the systems that people interact with to account for known human strengths and limitations so safety may be improved [32].

\section{Setting}

This study took place in two Canadian cities, Montreal and Québec City, from 2009-2012. While Montreal has a large multi-ethnic and multi-cultural population,
Québec City is more reflective of the demographics of the rest of the province of Québec, which is predominantly Caucasian, Catholic, and French-speaking [33]. Study participants reflected this portrait. Although both cities fell under the same provincial jurisdiction for healthcare, the reality was such that the criteria used to designate an individual to receive palliative home care and the services offered, varied across Centres locaux de services communautaires (CLSC), which are community services centres providing health and social services in peoples' homes.

\section{Data collection}

Based on the broadened conceptualization of home care safety $[7,21]$ data were collected using semi-structured interviews, photo "walkabouts", and focus groups all of which were digitally recorded. Following ethics approval, the research team relied on nurses and case managers from participating CLSCs to recruit participants. Eligible clients receiving palliative home care services were identified and contacted in order to determine their interest in learning about this study. Clients, caregivers, and providers who were interested and who agreed to release their names were contacted by the researcher to explain the study, answer questions, and arrange to meet with those still willing to participate.

There were three types of participants in this study namely palliative care clients, caregivers, and paid providers. Five households in each city participated resulting in a total of 33 interviews (note: in two households an additional provider was interviewed and in one household an additional caregiver). Client and caregiver interviews were conducted in the client's home in either English or French depending on their preference. In order to allow for more freedom in speaking about their respective concerns and insights, the interviews with clients and caregivers were conducted separately when possible. Following the interviews a photo "walkabout" was conducted, during which the client, caregiver, or both parties guided the interviewer through the home while describing their daily experiences and routines. 
Visual methods, such as photo narration are increasingly being used in social science and qualitative research as a way to encourage participant collaboration while accessing the experiences and voices of research participants $[34,35]$. Features such as stairs, areas or rooms in the home, devices, medications, and supplies that were linked to daily routines and any possible safety concerns were pointed out by the participant and were captured on digital camera by the researchers for later human factors analysis.

\section{Participants}

Clients and caregivers self-identified as Quebecois or Canadian from a variety of cultural groups (e.g., Belgian, Haitian, East Indian, Bosnian, and Jewish). There was an equal distribution of female and male clients whose mean age was 78 years (range $=66-89$ yrs.). All of the palliative designations were based on the client's cancer diagnosis (i.e., lung, prostate, colorectal, nasopharyngeal, and pancreatic cancer). In addition to cancer, some of the clients were also living with various chronic illnesses including congestive heart failure, chronic obstructive pulmonary disease, diabetes, renal failure, and rheumatoid arthritis. Nearly half the caregivers were women with a mean age of 70 years (range $=52-87$ yrs.), and all but one caregiver, who was the daughter of the client, were the spouses of the client. Clients and caregivers reported that their highest level of education achieved ranged from Grade 9 to a university degree.

Individual interviews with nurses $(\mathrm{n}=5)$, social workers $(\mathrm{n}=4)$, physiotherapist $(\mathrm{n}=1)$, and occupational therapist $(\mathrm{n}=1)$, who were most familiar with the participating clients and caregivers, were conducted at a time and place agreeable to the particular provider. To further enrich the data, focus groups [36] with paid providers were also conducted in each city. Three of the focus groups consisted of experienced professionals $(n=25)$ including physical and occupational therapists, nutritionists, spiritual leaders, physicians, while two were comprised of infirmière auxiliaire $(\mathrm{n}=11)$ who are generally referred to outside of Québec as home support workers and paid to provide home care services such as house cleaning, cooking etc. Providers were predominantly women $(98 \%)$ with a mean age of 53 years (range $26-59$ yrs.) who had been working in home care on average 11 years and 6 years specifically in palliative home care.

\section{Data analysis}

Digital recordings of the interviews and "photo walkabouts" were transcribed verbatim and uploaded into NVivo 8, a qualitative software program. With the broadened conceptualization of home care safety as the guiding framework, two researchers independently coded each transcript identifying patterns and the relationships among the patterns. Two members of the team, including a human factors engineer, similarly coded the photographic data independently. We compared each interview with subsequent interviews. A pattern was identified either by its frequency in the data and/or by the importance of the issue that emerged.

The analysis team convened regularly to identify recurring, converging, and diverging patterns in the data. Any discordance was discussed until consensus was reached. In this paper, the findings that directly link to the experiences, challenges, and insights from clients, their caregivers, and providers around palliative home care safety are presented.

\section{Results}

The four dimensions of safety namely physical, emotional, social, and functional safety $[7,22]$, described in Table 1, were used to frame the findings in this study. While the patterns have been listed separately, it is important to recognize there is some overlap, but not to the extent that patterns could be collapsed any further.

\section{Pattern 1: Safety risk due to the mismatch of physical space, equipment and supplies}

Safety risks were created for clients and caregivers when equipment and supplies designed for larger institutional spaces were used. This contributed to clutter, which created slipping and tripping hazards such as insufficient space to maneuver wheelchairs; hospital beds crowding bedrooms and living rooms; walkers that didn't work well on carpeting; and oxygen tanks and their tubing snaking in communal living areas. Storage of healthcare related supplies such as oxygen tanks, numerous medications, spare catheter bags and tubing or boxes of wound care dressings took up space and made it more difficult and potentially risky to navigate in bedrooms, living rooms, or wherever the equipment and supplies were stored in the home. Safety risks were also created by fluctuations and inconsistencies in the availability of proper equipment and supplies for home care. In some instances, not only did this increase the risk of falls or injuries to clients and caregivers, but added frustration during an already demanding time in their lives. The human factors analysis illustrated mismatches between equipment and living environments in the photographic data (Figure 1 and Figure 2).

\section{Pattern 2: Lack of preparation, training, and support for caregivers}

Safety risks existed because caregivers were generally untrained, felt ill-prepared, and received limited to no supervision or support to provide around-the-clock complex care to their loved one who was dying. This often resulted in unintentionally risky practices and 


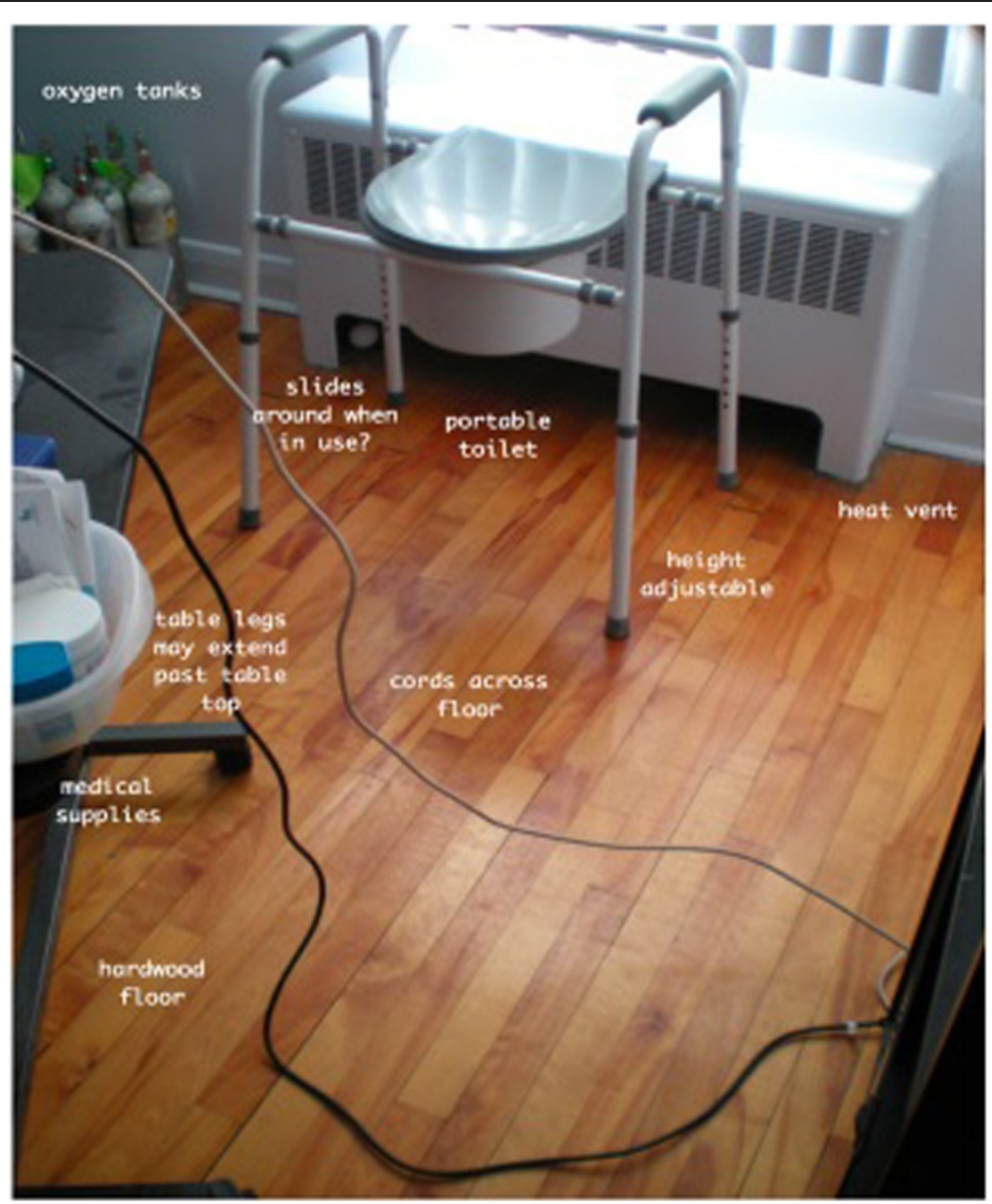

Figure 1 Equipment and oxygen supplies increasing physical clutter. Wires and tubing present tripping hazards, limited space for safe maneuvering.

situations that at times impacted the health and wellbeing of both the client and the caregiver.

I know they couldn't tell me exactly what is going to happen, but they didn't give me a clue. I had to guess at when to take her in to the hospital... that was to me the scariest, it's the not knowing what was going to happen, what was coming, what were the first things I had to do, stuff like that... Everything was learn as you go but that was very difficult to me... [CG]

... When my husband was dying, I took him home but I was terrified, what did I know about caring for someone who was dying? I phoned my doctor, very intuitive, very bright man, so long as he could do something for you... When he couldn't do something for you he checked out so I was really alone... [CG]

Providers shared their awareness of the degree of responsibility being imposed on caregivers stating that caregivers had limited knowledge or training and often had to very quickly learn how to manage care for their loved ones due to the very nature of the palliative home care scenario.

...we will teach them in the space of an hour how to give injections of morphine, but I remember the gentleman who told me: "You've had three years of training and then you ask us to do it in an hour..." [PRO]

Caregivers, often conscripted into their role, were in many cases unaware of the risks of injury and adverse events to themselves or their loved one. There were situations identified by providers where the caregiver and client did not recognize that some of their actions, often those normally performed by trained personnel in institutional settings, were placing the client and/or themselves at risk. For example one provider noted,

...I found out recently that her husband had given her suppository and he dis-impacted her when she was impacted [constipated] and I'm thinking: '... does he have the training for that?' [PRO] 


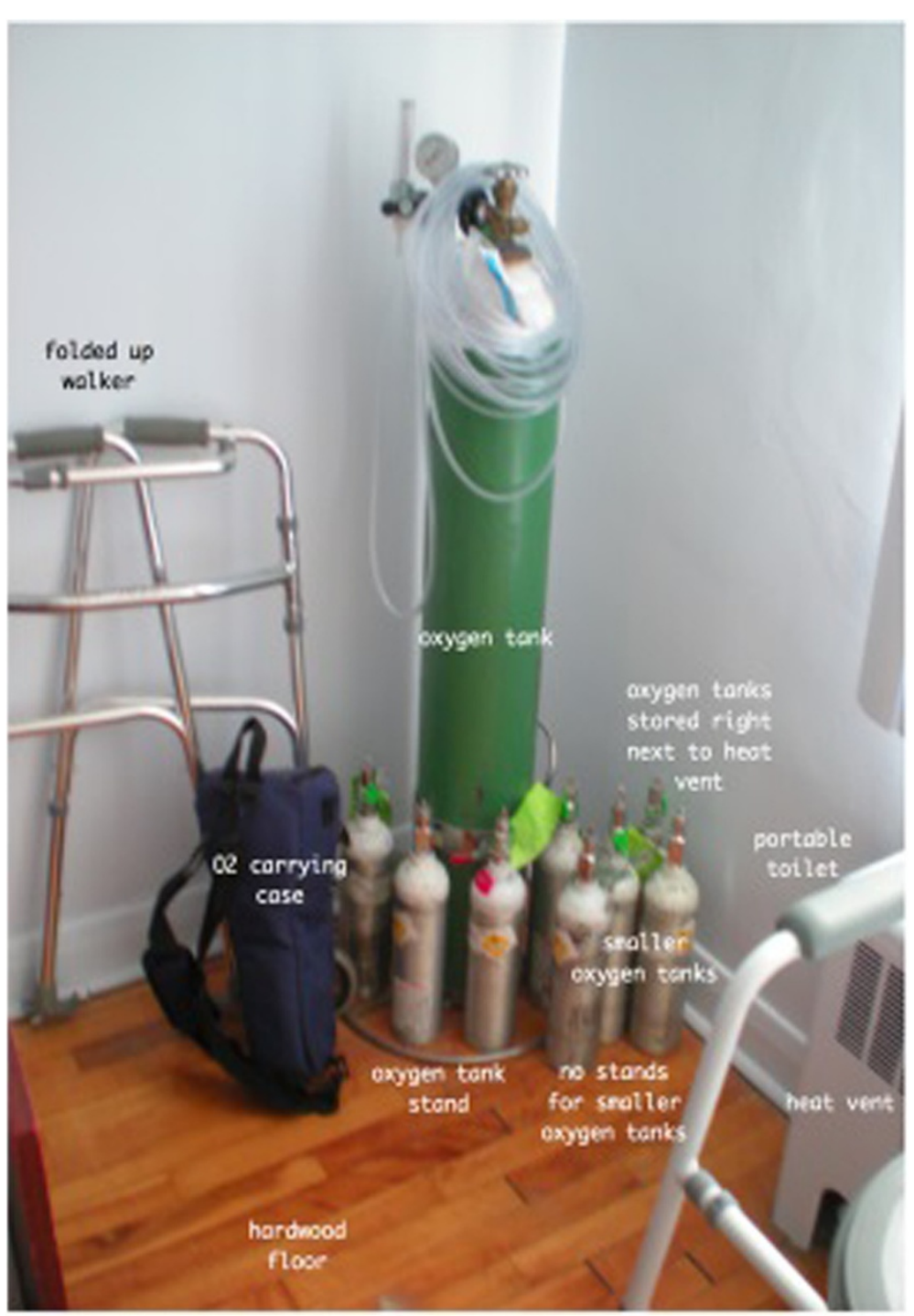

Figure 2 Spare oxygen tanks stored next to a heated vent. The client in this home continued to smoke in the presence of the oxygen.

Helping individuals who were weakened by their disease and in pain to bathe, transfer from the bed to a chair, to the toilet, or between rooms, often caused additional pain and discomfort, albeit unintentional. Indeed, as the client's health deteriorated, typically requiring exponentially more complex and time consuming care, these risks increased as the caregiver became increasingly fatigued and exhausted over the prolonged weeks and months. Furthermore, some of these caring activities placed both clients and caregivers at risk for slips, trips, and injuries.

If I have to always wash him by hand, it is not easy. I have already hurt my shoulder, I fell and all that, I do not know how long I will be able to wash him by hand? [CG]
Caregivers also had to manage unexpected and urgent situations that heightened the emotional, social, and functional distress for both clients and caregivers.

...there was one time when we went out together for some errands. He [CLI] suddenly says "I am going to have diarrhea now!" He couldn't help himself... poor guy was full of it all over his pants...

I had to tie my sweater around his waist and we asked the girl working in the clothing store if we could use her washroom.

I made him sit and told him not to worry...

I cleaned him up as best I could ... [CG]

Caregivers were frequently responsible for managing and administering multiple medications (including narcotics), 
often without any training. In contrast to hospitals, where professionals follow extensive and explicit policies and procedures about how to store, administer, and monitor medications, at home medications were managed irregularly. The human factors analysis of photographic data illustrated medications stored among non-medication related items, in cluttered locations, with other people's medications, and among expired medications, creating safety risks for all involved (Figure 3).

Knowledge of the types of medications caregivers administered or clients self-administered was at times vague, limited in terms of what a medication was prescribed for, and possible effects or contraindications. Clients and caregivers were not always aware that failure to execute one step or adding an additional step in a medication regime could cause an overdose, considerably diminish a medication's efficacy, worsen symptoms, increase the frequency of exacerbations, or cause other medication-related adverse events. Caregivers described the apprehension experienced pertaining to potentially forgetting to give medications and to giving too much of a narcotic such as morphine to manage pain.

\section{Pattern 3: Caregivers' health and wellbeing neglected by self and others}

Focusing on the client often led to neglect of the health and wellbeing of the caregiver, not only by the paid providers, but also by the caregivers themselves. Elderly caregivers gradually took on increased responsibilities while trying to balance pre-existing commitments, as well as their own physical and mental health challenges. In addition to being on call 24 hours a day caregivers' responsibilities often extended for weeks and even months without breaks or respite. Increased reliance on caregivers to assist with medications, transportation, client ambulation, communication and coordination with the care team, managing household tasks, and personal care, increased, as the client's capacity to manage once easily completed tasks diminished. Caregivers commonly neglected their own health issues and suffered extra stress caused by a feeling of heavy responsibility, the need to advocate for the client, and feelings of isolation - all on top of the emotional toll of knowing their loved one was going to die.

\section{...I have an arrhythmia, I have high blood pressure... she won't let me out. I have appointments, I have prostate cancer, and I can't even go to my appointments since September because she says: You have to stay with me... [CG]}

In addition to caregivers' various pre-existing conditions and chronic illnesses, caregivers also reported persistent fatigue from interrupted sleep patterns due to being constantly vigilant of the client's needs as they were confused, needed pain relief, help repositioning, or assistance with toileting during the night.

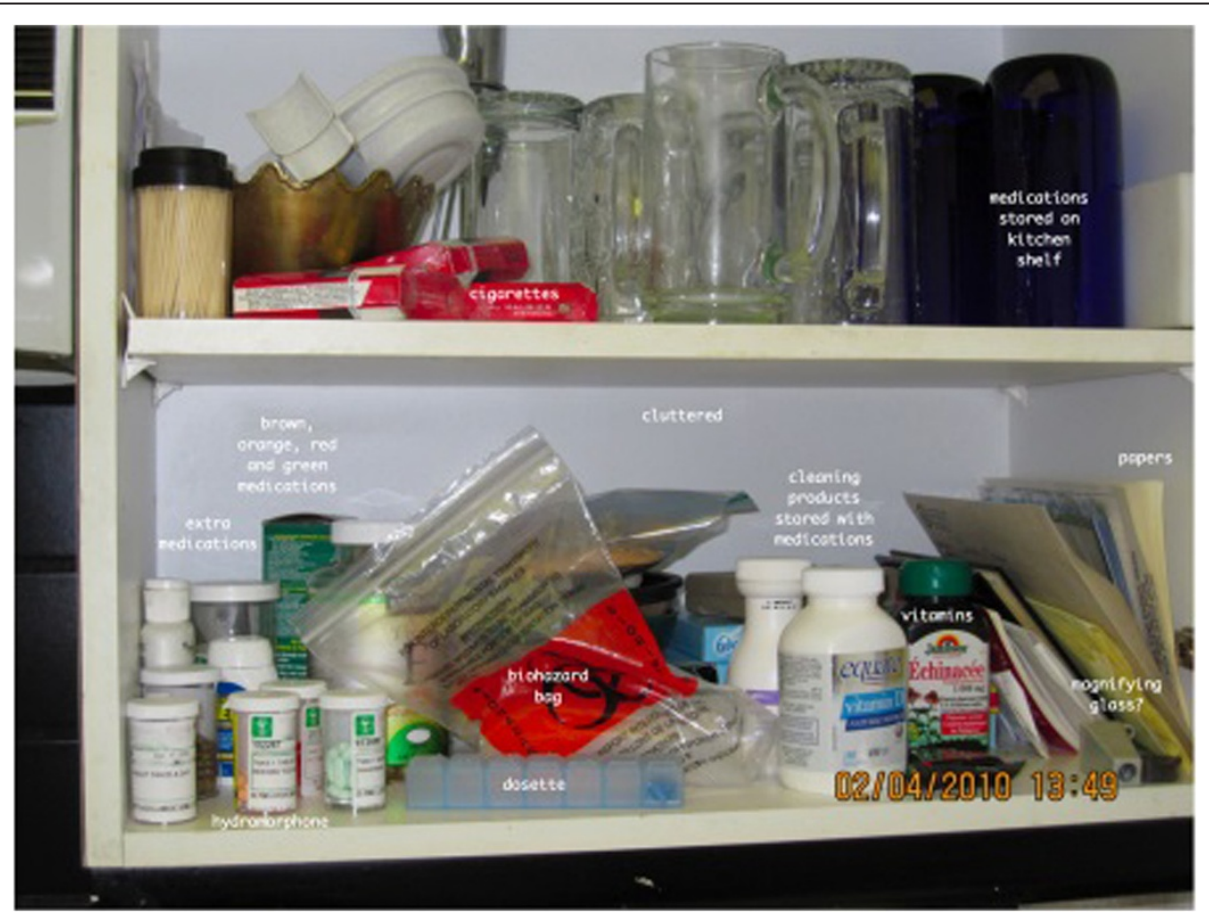

Figure 3 Various types of medications were stored with everyday items such as cleaning products, glasses, plastic containers, cigarettes, a biohazard bag, empty medication containers and paper work. 
...I found it terribly difficult... he got up at night and did things...weird things but he couldn't remember the following morning. It exhausted me terribly when I was not sleeping... he can do anything at night! I desperately need to sleep at night or I'm screwed because I have no reserves and I worry that if there was something I may be sleepy or not fully present... [CG]

she's just so dedicated to her husband but she put her health way after his. She needed knee surgery, she needed to go to the doctor... it was to the point where one day she just fell... [PRO]

Caregivers reported feelings of a diminished sense of control, powerlessness and helplessness. Caregivers said they often felt unappreciated and excluded from discussions among healthcare professionals about the client's care and this was in spite of the system relying on them to take on the responsibility of providing the majority of care in the home.

The social worker doesn't even want to talk to me. As a matter of fact, she won't even let me in the room when she speaks to [CLI]. It's sick. That's the other part, but I don't care! I'm doing the best I can. Under very trying and very demanding circumstances at times... I don't know what else to do... [CG]

In some instances already strained relationships between clients and caregivers were exacerbated within this palliative home care context. Providers acknowledged that caregivers often received little attention from them because they (providers) were not mandated nor did they have time to address caregiver stress and illness. Indeed, providers shared they often lacked the necessary expertise to attend to some of the complex situations they were confronted when delivering palliative home care.

[Referencing abusive relationship] You know we can't fix problems that have been there for many years. It only escalates when there's an illness, a life threatening illness. And you can't fix it; you only can start from where you're at. You can't go back... if you gotta go back then that's more therapy than I have the expertise for... [PRO]

\section{Pattern 4: changing roles lead to tensions}

As the needs and responsibilities of clients and caregivers increased exponentially, they were often compelled to renegotiate their existing roles and relationships with each other, family members, friends, and the healthcare system. Previous and existing family tensions, concerns about finances, exhaustion, frustration and apprehension regarding the inevitability of the client's death, in combination with not knowing when the end would come led to disagreements, extreme anger or resentment between some clients and caregivers. This inadvertently created safety risks for all involved:

a lot of times they [CG] accept to take them home because they know they're only going to have them $[C L]$ for a short period of time and they have accepted it mentally but sometimes they [CL] live longer and what happens is the caregiver gets burnt out ... what happens is they'll become more rough with the client, not intentionally but because of the frustration, they can grab them unsafely sometimes, or yell ... [PRO]

her children got her to change her will so they are the beneficiaries, the executors. I wasn't going to sit and fight with them, I'm gonna let them do what they gotta do, that's basically what it is and they want to control her, the kids want to control her ...[CG]

Caregivers felt obligated to provide incrementally demanding care because there was often no one else available to do it. In one household an ex- girlfriend who lived in the apartment above the client partnered with the client's current girlfriend to cover his care needs around the clock. In another household where the couple had been separated for years, the wife who had been living apart from her husband became his caregiver now that he was dying. Despite their marital rift, this couple renegotiated their relationship resulting in the client moving back into her house and into her bedroom so that she could help him with his activities of daily living, pain control etc. She explained her acceptance of the situation.

I became his mother, him my child in a certain sense. Well he is sick, there are things that I have to forget, but you know we are compassionate to his plight it would not change anything anyway. We both had a good cry, it would not change anything? No point to be in sorrow all the time... [CG]

In some cases, caregivers fell ill themselves, and in these situations roles were reversed. Some clients described how they took on the role of caregiver, despite being terminally ill themselves. The definition of roles was determined simply by who was the sickest at the time, and roles were reciprocated frequently. As illustrated by a caregiver who was diabetic and caring for her bedridden husband,

I had a reaction, and my blood sugar dumped very suddenly. I was like shaking and just almost passedout. That was scary. That was scary for him [CLI] ... He was very afraid. But luckily he had some dried 
fruits in his drawer... I was still conscious. I was still aware what was happening and all that...I was like I've got to have something sweet. If I had actually passed out he could still get the phone of course, and call $911 \ldots$ [CG]

I must say again, my wife is looking after me despite the fact that she has a severe illness herself... [CLI] It's only in the last year, you see, because he [CLI] was the caregiver before. Yes, because she [CG]... physically, in many ways, she was the one who had more sickness. [PRO]

These renegotiated roles and responsibilities frequently added a palpable layer of stress to existing strained relationships among the caregiver and other family members, leading to misunderstandings, arguments, and increased tensions.

\section{Pattern 5: autonomy to make less than safe choices}

Living at home as independently as possible with some sense of personal control and normalcy was central for clients. Indeed, the emotional security rooted in the thought of dying at home was paramount to their perception for safety and the safety of those around them.

I could probably walk without the walker, but I am a little wobbly, and I know the therapist would like me to remove all my scatter rugs and I don't want to do that, it would break my heart to have the house empty out like that, so I'm just aware of it and I try to be very careful not to hook into it and I want to leave the rugs... [CLI]

sometimes I see him go up or down this small staircase. But I learned not to bug him about it anymore. Even if it's risky, even if it were better if he didn't do it [climb steep staircase], it's his choice... [CG]

Providers offered health education and suggested strategies for care, but ultimately the clients and caregivers decided what they would and would not do.

We will propose solutions but it is up to them to decide what to do with the suggestions that we make, it is for them to make the choice. And that is what the people love to hear. They think "it is my home...." So even if they are not safe, we cannot demand anything... [PRO]

One example was an oxygen-dependent client who had a large sign on her front door warning visitors that oxygen was in use. However, anyone stepping into the apartment was immediately hit with a wall of cigarette smoke. When discussing the sign, the client explained that she made sure never to smoke in the room where the oxygen tank was located because she knew "how dangerous it can be" [CLI].

In some cases, such as during moving and lifting transfers, safety risks were created when clients and/or caregivers were reluctant to use equipment provided to them in order to mitigate safety risks and to improve client comfort.

If we do not have a hoist and we know that with a hoist it would be more comfortable and safer to install the client in his bed, or in a chair that is there in the living room or in his room but she or he [CG] says ... No, no I will take him, I will slide him... if spouses or caregivers are reluctant to use any kind of new devices and other things, it can be dangerous. [PRO]

Acknowledging that home was not always the safest place for terminally ill clients as their illness progressed was a sensitive topic. Observing various physical, emotional, social, and functional safety risks, often on a daily basis, created emotional dilemmas for healthcare providers and caregivers requiring them to regularly reevaluate the home care situation.

\section{sometimes I feel that if they don't follow our recommendations or our ways of setting our safety limits, we step back. Of course, we have our own workers' safety to protect, but how about the client's safety? How about the neighborhood's safety? The building's safety? .... We can say, "Either it's our way, or the highway." Because we have rules and standards to abide by... it's putting other people at risk... [PRO]}

The personal and professional thresholds of safety risks for healthcare providers needed to be offset with the client's and caregiver's choice to live with certain risks. Although they strived to respect the wishes of terminally ill clients receiving home care, in some cases this created dilemmas for providers in terms of the safety risks posed. This perpetual balancing act is a key element of safety in the palliative home care scenario.

\section{Pattern 6: revolving door of providers compromises trust and confidence}

Similar to other Canadian provinces, the way in which home care services are organized in Québec often created a revolving door of paid providers which compromised trust, confidence, and emotional safety. Providers who were unfamiliar with a particular household posed a risk to attaining and maintaining trust as well as continuity of care. The revolving door also hindered at times the accurate assessment and appropriate response to 
changes in a client's situation, which although subtle at times, could be critical and shift quickly.

If it's different nurses all the time, even if they are giving care, in my head, it's not as safe as having the same nurses who are familiar with the situation... [CLI]

Clients described their concern, sense of vulnerability, and even fear related to having a multitude of people with different abilities and ways of being, attending to their most personal and most intimate needs.

\section{Last week another nurse came ... and I was a mess because I don't think she had ever put a Foley [catheter] into a woman before and she would say things like "does it go in the vagina, is the vagina open", I said 'what?' I said 'No! It goes into the urethra!' Till she got it in, you imagine how stressed I was?}

Fragmentation of services, high rates of care provider turnover, and communication difficulties between the home and home care services led clients and caregivers to share that they felt unsafe and sensed a lack of control over who entered their home at different times of the day or night.

I was getting the lady for the respite... We're also getting a cleaning person coming in from the CLSC... the first one was an excellent cleaner, but boy did she talk a lot. She would know all our business. And then I had another one who smoked like crazy, she can't smoke in here because of the oxygen, but on her clothes you smelt nothing but cigarettes... [CLI]

In response to feeling stressed, frustrated, and less safe due to the number of different providers, some clients and caregivers re-negotiated the terms of the home care service relationship or the terms of the client's care, (e.g., they requested specific services, insisted on consistency of providers, and identified unmet needs of the client that had been missed because of inadequate assessment). However this was after the acceptance of the services in the first place and not before, or as the home care contract was being planned. Clients and caregivers had to experience and recognize the disruption and perceive a threat to their safety and sense a loss of control in their home in order to try and regain some sense of control over the situation. In some cases this made clients and caregivers so uncomfortable they turned down some or all of the services they could have received.

A lack of continuity of staff resulted in providers feeling they lacked the time required to communicate properly with clients and caregivers. Providers were cognizant of and frustrated with system and work design challenges such as: staff shortages; rationing of time allocated to individual visits; clients being discharged from hospital to home with little or no notification to home care services, and large caseloads all of which placed clients and caregivers at risk.

passing in the same week, there can be seven different people even from agencies who don't really know the client. I think our clients need stability and people they know... [PRO]

"...I hope they didn't send him home on the weekend and he's dead. You know, that was my biggest, worst fear; he had no family ...It just happens sometimes. They don't inform us, they just send them home... [PRO]

\section{Discussion}

Although much has been written about the experiences and challenges of palliative care including palliative care at home, this study contributes new knowledge by using a safety lens to describe and explain the experiences of clients receiving palliative home care services as well as their caregivers and paid providers. Our findings support the broadened conceptualization of home care safety namely: how the safety of the client and caregiver are inextricably linked; the multiple dimensions of home care safety, including physical, emotional, social, and functional safety; that the home is an unregulated and uncontrolled site for providing care in contrast to hospitals or other institutional settings; and that clients and caregivers have the autonomy to live and take risks in their own home $[7,22]$. Based on these realities, which were central in framing the findings from this study, we are structuring this discussion by putting forward five key messages to help mitigate the home care safety risks to clients and caregivers.

\section{Key message \# 1: consider the client and caregiver(s) as the unit of care}

The safety of the client is inextricably linked to the safety of the caregiver $[7,22]$. Caregivers in this study often neglected their own health needs, felt compelled to renegotiate their roles and relationships with the person they were caring for, stated that they experienced stress from the responsibility of caring and the apprehension of potentially committing a serious or fatal error, all the while trying to honour the client's wish to maintain some level of autonomy and to die at home with dignity. Consistent with earlier work [37] caregivers in this study were seldom considered part of the healthcare team, seldom consulted regarding the plan of care, or acknowledged 
in terms of their increasing stress and deteriorating health. It is therefore imperative that beginning with the assessment stage of palliative home care services providers focus on the client and caregiver together as the unit of care, and not just the client as per the philosophy of palliative care [38]. A means of accomplishing this would be to include a specific caregiver assessment at the onset of home care service provision to consider how ready and willing a caregiver is to take on the role of caregiver and to gain a better understanding of that particular family system. Moreover, having anticipatory guidance for caregiver about what to expect and where they can access supports would be useful to those taking on this responsibility.

\section{Key message \#2: prepare and train caregivers to manage the complexity of issues}

For many, becoming a caregiver is a first time experience. When discharged from hospital it is taken for granted that those closest to the client will provide the care required, with little recognition or reimbursement. Referrals often provide incomplete information for home care providers putting the caregiver and client in a less than desirable situation from the outset $[39,40]$. Often conscripted into the role, caregivers are increasingly relied upon by the health system to provide the lion's share of the care, with little or no attention paid to the caregivers' health condition, concerns or preoccupations [20]. In this study, some caregivers did not grasp the exponential nature of care needs that would ultimately result from the client's deteriorating health situations. Caregivers and clients also reported that paid providers typically underestimated the nature and extent of care and support required. Caregivers were vulnerable and often overextended by the time palliative home care services were offered or engaged, or became so as the burden of care increased and the caregiving period lengthened. Caregivers have previously reported inadequate knowledge [41] particularly related to pain management, navigating an uncoordinated home care system, no hands-on learning, and not knowing what to expect as an illness progresses [42]. This lack of knowledge may well be a contributing factor to the feelings of powerlessness and helplessness that caregivers described when providing palliative care [43] or the feeling of loss of control $[44,45]$.

Peoples' homes are generally not designed for and thus seldom suited to the provision of healthcare. They can become cluttered and poorly maintained environments $[6,9]$. Several challenges such as the mismatch between the available physical space and storage requirements of equipment and supplies in private homes, [46]; a lack of training or preparation to meet the complex demands, tailored information about available resources for clients and caregivers [47]; and the need to teach clients and caregivers practical skills and information [46,48-52], have all been previously reported but without the link to safety. It is important to provide tailored and accessible information about the services available; training related to lifting and handling; medication management and administration; and dealing with symptoms and other forms of caregiver distress. A recent study found that caregivers learn through processes such as trial and error, actively seeking needed information and guidance, applying knowledge and skills from previous experience, and reflecting on their current experiences [53]. As in this study, caregivers generally preferred and appreciated a supported or guided learning process that involved being shown or explained by others, instead of learning reactively after a crisis. Thus, preparing and guiding caregivers to manage the complexity of practical, emotional, and cognitive challenges associated with caring for the person who is dying, is pivotal to ensuring their physical, emotional, social, and functional safety as well as that of the person for whom they are caring [46-50]. This level of support for caregivers is essential to help them cope, enable them to recognize when they need additional support, and how to seek it, especially when care providers are not present.

\section{Key message \# 3: conduct regular assessments to monitor and detect changes in the unit of care and their changing needs}

Safety at the end of life involves the inter-relatedness of the client, family members, caregivers, and healthcare providers. Trust and confidence in healthcare providers have been shown to be critical to a feeling of safety at home [46-49,54,55]. Providing nurses and support workers as part of palliative home care services is accepted as being helpful, yet it also has the potential to compromise trust, confidence and the emotional safety of clients and caregivers if this help is seen as a revolving door of different home care providers. This revolving door setup was typically due to the organisational challenges of scheduling, staff turnover, and burnout. It has the potential to compromise the safety of palliative care clients because of poor communication amongst home care staff and a failure to pick-up on small and subtle changes in the client and caregiver's situation over time [56]. Routine assessments of the caregiver's health and well-being, along with the client's should be part of home care. Conducting ongoing reassessments of clients and caregivers should include updating and adapting care and supports to their changing health needs.

\section{Key message \# 4: recognize, acknowledge, and respect clients' and caregivers' autonomy to make less than safe choices}

In contrast to hospitals or other institutional healthcare facilities where staff are required to follow standardized 
policies and procedures, clients and caregivers have the freedom and the autonomy to make less than safe choices in their homes. Recognizing that the perception of safety may differ for each stakeholder and for each household is pivotal to the goals of home care $[46,48]$. Recipients of home care services make less than safe choices for a number of reasons including that nothing bad has happened to them yet, they are unable to envision an issue, or they do not have access to the right or complete information that would help them manage their situation. Furthermore, there are situations where despite being armed with adequate and pertinent information clients and caregivers are at times willing to accept certain safety risks posed by some of their choices and decisions of how they want to live at home [9]. Whether or not they realize the implications of each of their decisions, having the autonomy to make such choices is fundamental to home care. Similar to the high value placed on autonomy found in this study, the main advantages perceived by clients, their families, caregivers, and providers to living at home is the ability to be together as a family and to maintain a perception of normal life providing a sense of feeling safe $[46,48]$. In this way, the decision to accept certain physical safety risks may be a tradeoff between different types of contributors to safety such emotional, social, or functional safety [19]. Table 2 offers some additional examples of the various dimensions of safety as well as their impact and interrelatedness between clients and caregivers.

The providers in our study spoke of the need to respect the way of life of the clients and caregivers and the entirety of their needs and concerns rather than focusing solely on physical safety. This is one of the hallmarks of home care and home care safety, allowing the clients and caregivers to make less than safe choices when safety is considered from a physical point of view. Caregiver safety is enabled by providers having an attitude that does not judge or diminish the caregiver, affirms

Table 2 Additional examples of the various dimensions of safety risks

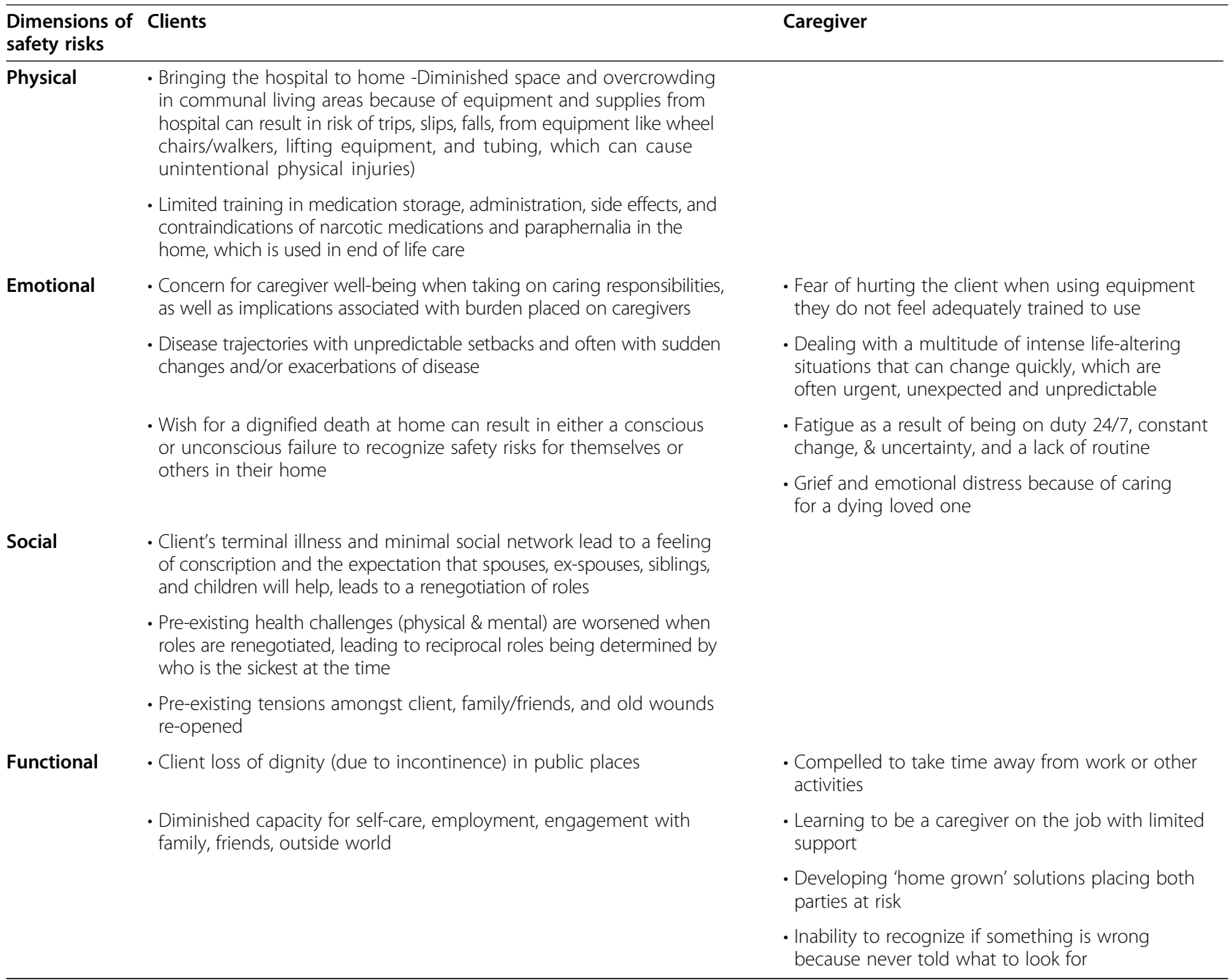


their concerns and efforts, and that enables the client, family, and caregivers to live their lives as they wish, to the extent possible [47]. This suggests that while the family's choice to prioritise other concerns over those of physical safety the broader concept of safety is actually increased.

\section{Key message \# 5: ensure continuity of and coordination of quality care for the unit of care in each household} Home care is an assortment of services offered by an ever-changing roster of providers. For the palliative care population transitions between hospital and home is relatively common for acute episodes or symptom management. These recurrent transitions present challenges to sharing documentation and communication, challenges for which the risks are heightened at points of transfer across sectors [57-59]. Assigning a cross -sector case manager who has comprehensive understanding of a particular household with the authority and responsibility to minimize disruptions should be considered as a step towards ensuring continuity, mitigating risks, and coordinating care.

\section{Conclusion}

Patient safety as conceptualized in institutional settings does not fit well with home care safety $[7,22]$. The safety issues presented here within the context of palliative home care draws attention not only to safety issues of the client but also illustrates the interconnectedness between the client's safety with that of their caregivers. This study highlights how to expand the safety framework for home care to include the emotional, social, and functional dimensions of safety along with physical safety. Future research needs to maintain a systems perspective including focusing on the client and caregiver(s) as the "unit of care", not just the client. Moreover, policy and practice changes are needed to ensure that assessments and care-plans are tailored and adjusted on an ongoing basis as the situation and needs for the unit of care evolve. Finally, in order to mitigate risks and ensure quality, current and potential recipients of home care need to be empowered to request and expect home care services tailored to their particular unit of care.

\section{Endnote}

${ }^{a}$ In our work, home care patients are referred to as "clients", and the term "caregivers" signifies unpaid family, friends, or neighbours who support and provide care for the client. "Providers" are professional - regulated or unregulated - individuals who are paid to provide home care services to clients.

\begin{abstract}
Abbreviations
CLI: Client; CG: Caregiver; CLSC: Centres locaux de services communautaires (Local community services centre); PRO: Paid Providers; VON: Victorian Order of Nurses Canada.
\end{abstract}

\section{Competing interests}

The authors declare that they have no competing interests.

\section{Authors' contributions}

$A L, R C, K S, A F$, and TE participated in the study conception, and design. $A L$ coordinated and managed the all aspects of the project. MG \& TE provided Human Factors analysis of photographic data. AL, LT, RC, KS, MG, AF, TE, and AW participated in the analysis and manuscript drafts. All authors read and approved the final manuscript.

\section{Acknowledgements}

This study was supported in part by the Canadian Institutes for Health Research, le Ministère de la Santé et des Services sociaux, Accreditation Canada, Canadian Institute for Health Information, University Health Network, and the Canadian Patient Safety Institute. As a Chercheure Boursière, Dr. Ariella Lang was supported by Fonds de Recherche Santé Québec. Réseau de recherche en interventions en sciences infirmières du Québec (RRISIQ) and McGill University provided financial support to Dr. Lang for this publication. The authors would like to thank all of the individuals who recruited and made the initial contact with the families as well as those who participated in the interviews and focus groups. A special thanks is also extended to the individuals and caregivers who participated by generously opening their homes and lives in order to make this project a reality. We would also like to thank Jo-Anne MacDonald and Michelle Proulx for their input into the analysis of the data and Janet Purvis from VON Canada and for her invaluable comments and edits to the final manuscript.

\section{Author details}

${ }^{1}$ Victorian Order of Nurses (VON) Canada, 2315 St. Laurent Blvd, Suite 100, Ottawa, ON K1G 4J8, Canada. ${ }^{2}$ Program in Palliative Care Departments of Oncology and Medicine McGill University, Jewish General Hospital, H3.64 3755 Cote Ste. Catherine Road, Montreal, QC H3T 1E2, Canada. ${ }^{3}$ School of Nursing and Centre on Aging, University of Victoria, PO Box 1700 STN CSC, Victoria, BC V8W 2Y2, Canada. ${ }^{4}$ Centre for Global eHealth Innovation, Toronto General Hospital, 190 Elizabeth Street, RFE 4-423, Toronto, ON M5G 2C4, Canada. ${ }^{5}$ Ingram School of Nursing, McGill University, 3506 University Street, Montreal, QC H3A 2A7, Canada. ${ }^{6}$ School of Geography and Earth Sciences, McMaster University, 1280 Main Street, West Hamilton, ON L8S 4 K1, Canada.

Received: 30 December 2014 Accepted: 18 December 2014 Published: 27 May 2015

\section{References}

1. Bacon J. The palliative approach: Improving care for Canadians with life-limiting illnesses. Ottawa, ON: Canadian Hospice Palliative Care Association; 2012.

2. Karlsson C, Berggren I. Dignified end-of-life care in the patients' own homes. Nurs Ethics. 2011;18:374-85.

3. Gomes B, Higginson IJ. Factors influencing death at home in terminally ill patients with cancer: systematic review. BMJ. 2006;4:515-21.

4. Lang A, Macdonald M, Storch J, Elliott K, Stevenson L, Lacroix H, et al. Home care safety perspectives from clients, family members, caregivers and paid providers. Healthcare Q. 2009;12 Spec No Patient:97-101.

5. Stajduhar Kl. Examining the perspectives of family members involved in the delivery of palliative care at home. J Palliat Care. 2003;19:27-35.

6. Safety at Home: A Pan-Canadian Home Care Safety Study. Canadian Patient Safety Institute; [http://www.patientsafetyinstitute.ca/English/research/ commissionedResearch/PatientClientSafetyinHomeCare/Documents/ Reports/Doran\%20Project\%20Summary.pdf]

7. Lang A, Edwards N, Fleiszer A. Safety in home care: a broadened perspective of patient safety. Int J Qual Health Care. 2008;20:130-5.

8. Quality Interagency Coordination Task Force. National Summit on Medical Errors and Patient Safety Research. http://archive.ahrq.gov/quic/summit/ summary1.htm.

9. Lang A, Macdonald MT, Storch J, Stevenson L, Mitchell L, Barber T, et al. Researching triads in home care: perceptions of safety from home care 
clients, their caregivers, and providers. Home Health Care Manag Pract. 2013;26:59-71.

10. Grande G, Stajduhar K, Aoun S, Toye C, Funk L, Addington-Hall J, et al. Supporting lay carers in end of life care: current gaps and future priorities. J Palliat Med. 2009;23:339-44.

11. Stajduhar Kl, Davies B. Variations in and factors influencing family members' decisions for palliative home care. J Palliat Med. 2005;19:21-32.

12. Hudson P, Payne S. Family caregivers and palliative care: current status and agenda for the future. J Palliat Med. 2011;14:864-9.

13. Lynn JS,J. Improving care for the end of life: a sourcebook for clinicians and managers. 2nd ed. New York: Oxford University Press; 2007.

14. Health Care in Canada. A focus on seniors and aging. Ottawa, Ont: Canadian Institute for Health Information; 2011.

15. Rosenburg J. Whose business is dying? death, the home and palliative care. Cultural Stud Rev. 2011;17:15-30.

16. Harrison A, Verhoef M. Understanding coordination of care from the consumer's perspective in a regional health system. BMC Health Serv Res. 2002;37:1031-54

17. Lehoux P. Patients' perspectives on high-tech home care: a qualitative inquiry into the user-friendliness of four technologies. BMC Health Serv Res. 2004;4:28.

18. Donovan R, Williams A, Stajduhar K, Brazil K, Marshall D. The influence of culture on home-based family caregiving at end-of-life: a case study of Dutch reformed family care givers in Ontario, Canada. Soc Sci Med. 2011;72:338-46.

19. Macdonald M, Lang A. Safety in Home Care for Unpaid Caregivers: A Scoping Literature Review. Alberta, Canada: Canadian Patient Safety Institute; 2011. http://www.patientsafetyinstitute.ca/English/research/ commissionedResearch/SafetyinHomeCare/Documents/MacDonald/ MacDonald,\%20Marilyn_Caregiver\%20Safety_Final\%20Report\%20ENG.pdf.

20. Macdonald M, Lang A, Storch J, Stevenson L, Donaldson S, Barber T, et al. Home care safety markers: a scoping review. Home Health Care Serv Q. 2013;32:126-48.

21. Lang A, Edwards N, Hoffman C, Shamian J, Benjamin K, Rowe M. Broadening the patient safety agenda to include home care services. Healthcare Q. 2006;9 Spec No:124-6.

22. Lang A, Edwards N. Safety in home care: background paper for round table discussion. Edmonton, Alberta: Canadian Patient Safety Institute; 2006.

23. Macdonald M, Lang A, Storch J, Stevenson L, Elliott K, Lacroix H, et al. Safety in home care for unpaid caregivers. Canada: Canadian Patient Safety Institute; 2010

24. Macdonald M, Lang A, Macdonald J. Mapping a research agenda for home care safety: perspectives from researchers, providers and decision-makers. Can J Aging. 2011;11:48-54.

25. Macdonald M, Lang A. Applying risk society theory to findings of a scoping review on caregiver safety. Health Soc Care Commun. 2014;22:124-33.

26. Macdonald MT, Lang A, Storch J, Stevenson L, Barber T, laboni K, et al. Examining markers of safety in homecare using the international classification for patient safety. BMC Health Serv Res. 2013;13:191.

27. Stevenson L, Lang A, Macdonald M, Archer J, Berlanda C. Safety in home care: thinking outside the hospital box. Healthcare Q. 2012;15 Spec No:68-72.

28. Thorne S. Interpretive description. Walnut Creek, CA: Left Coast Press; 2008.

29. Stokols D. Translating social ecological theory into guidelines for community health promotion. Am J Health Promot. 1996;10:282-98.

30. Green LW, Richard L, Potvin L. Ecological foundations of health promotion. Am J Health Promot. 1996:10:270-81.

31. Sallis JF, Owen N. Ecological models. In: Glanz K, Lewis FM, Rimer BK, editors. Health behavior and health education: Theory, research, and practice. Mississauga, ON: Joney-Bass; 1997. p. 403-24.

32. Henriksen $\mathrm{K}$, Joseph A, Zayas-Caban T. The human factors of home health care: a conceptual model for examining safety and quality concerns. J Patient Saf. 2009;5:229-36.

33. [http://www.immigration-quebec.gouv.qc.ca/en/choose-quebec/commonvalues/index.html]

34. Liebenberg L, Didkowsky N, Ungar M. Analysing image-based data using grounded theory: the negotiating resilience project. Vis Stud. 2012;27:59-74.

35. Pink S. Interdisciplinary agendas in visual research: re-situating visual anthropology. Vis Stud. 2003;18:179-92.

36. Krueger $\mathrm{R}$, Casey M. Focus groups. A practical guide for applied research. 3rd edition edn. Thousand Oaks, CA: Sage Publications; 2000.

37. Reinhart SC, Levine C, Samis S. Home alone: family caregivers providing complex chronic care. New York: United Hospital Fund; 2012.
38. Definition of Palliative Care: World Health Organization; 2013. Retrieved from: http://www.who.int/cancer/palliative/definition/en/.

39. Dow B, McDonald J. The invisible contract: shifting care from the hospital to the home. Aust Health Rev. 2007;31:193-202.

40. Stevenson L, McRae C, Mughal W. Moving to a culture of safety in community home health care. J Health Serv Res Polic. 2008;13:20-4.

41. Docherty A, Owens A, Asadi-Lari M, Petchey R, Williams J, Carter Y. Knowledge and information needs of informal caregivers in palliative care: a qualitative systematic review. J Palliat Med. 2008;22:153-71.

42. Dunbrack J. The information needs of informal caregivers involved in providing support to a critically ill loved one: A synthesis report prepared for Health Canada. Ottawa, ON: Health Canada; 2005. http://cna-aiic.ca/ $\sim /$ media/cna/page-content/pdf-.

43. Milberg A, Stranng P, Jakobsson M. Next of kin's experience of powerlessness and helplessness in palliative home care. Support Care Cancer. 2004;12:120-8.

44. Munck B, Fridlund B, Martensson J. Next-of-kin caregivers in palliative home care - from control to loss of control. J Adv Nurs. 2008;64:578-86.

45. Vallerand $\mathrm{AH}$, Saunders MM, Anthony M. Perceptions of Control Over Pain by Patients with Cancer and Their Caregivers. Pain Management Nursing 2007:8(2):55-63. doi:10.1016/j.pmn.2007.02.001.

46. Appelin G, Broback G, Bertero C. A comprehensive picture of palliative care at home from the people involved. EJON. 2005;9:315-24.

47. Öhlén J, Andershed B, Berg C, Frid I, Palm CA, Ternestedt BM, et al. Relatives in end-of-life care-part 2: a theory for enabling safety. J Clin Nurs. 2007;16:382-90.

48. Appelin G, Bertero C. Patients' experiences of palliative care in the home: a phenomenological study of a Swedish sample. Cancer Nurs. 2004;27:65-70.

49. Funk L, Stajduhar K, Toye C, Aoun S, Grande G, Todd C. Part 2: Home-based family caregiving at the end of life: a comprehensive review of published qualitative research (1998-2008). J Palliat Med. 2010;24:594-607.

50. Jansma FF, Schure LM, de Jong BM. Support requirements for caregivers of patients with palliative cancer. Patient Edu Couns. 2005;58:182-6.

51. Mehta A, Cohen SR, Carnevale FA, Ezer H, Ducharme F. Family caregivers of palliative cancer patients at home: the puzzle of pain management. J Palliat Care. 2010;26:78-87.

52. Mehta A, Cohen SR, Ezer H, Carnevale FA, Ducharme F. Striving to respond to palliative care Patients' pain at home: a puzzle for family caregivers. Oncol Nurs Forum. 2011;38:E37-45.

53. Stajduhar Kl, Funk L, Outcalt L. Family caregiver learning: how family caregivers learn to provide care at the end of life: a qualitative secondary analysis of four datasets. J Palliat Med. 2013;27:657-64.

54. Cohen SR, Leis A. What determines the quality of life of terminally ill cancer patients from their own perspective? J Palliat Care. 2002;18:48-58.

55. Heyland DK, Cook DJ, Rocker GM, Dodek PM, Kutsogiannis DJ, Skrobik Y, et al. Defining priorities for improving end-of-life care in Canada. CMAJ. 2010;182:E747-752.

56. Blais $R$, Sears NA, Doran D, Baker GR, Macdonald M, Mitchell L, et al. Assessing adverse events among home care clients in three Canadian provinces using chart review. BMJ Quality \& Safety. 2013;22(12):989-997. doi:10.1136/bmjqs-2013-002039.

57. Forster AJ, Clark HD, Menard A, Dupuis N, Chernish R, Chandok N, et al. Adverse events among medical patients after discharge from hospital. CMAJ. 2004;170:345-9.

58. Forster AJ, Murff HJ, Peterson JF, Gandhi TK, Bates DW. The incidence and severity of adverse events affecting patients after discharge from the hospital. Ann Intern Med. 2003;138:161-7.

59. Forster AJ, Murff HJ, Peterson JF, Gandhi TK, Bates DW. Adverse drug events occurring following hospital discharge. J Gen Intern Med. 2005;20:317-23.

doi:10.1186/2056-5917-1-3

Cite this article as: Lang et al:: Client, caregiver, and provider perspectives of safety in palliative home care: a mixed method design. Safety in Health 2015 1:3. 